\title{
Prevalência das dermatopatias não-tumorais em cães do município de Santa Maria, Rio Grande do Sul (2005-2008) ${ }^{1}$
}

\author{
Tatiana M. Souza ${ }^{2}$, Rafael A. Fighera ${ }^{3}$, Claudete Schmidt ${ }^{4}$, Anelise H. \\ Réquia ${ }^{5}$, Juliana S. Brum ${ }^{6}$, Tessie B. Martins ${ }^{6}$ e Claudio S.L. Barros ${ }^{3}$
}

\begin{abstract}
Souza T.M., Fighera R.A., Schmidt C., Réquia A.H., Brum J.S., Martins T.B. \& Barros C.S.L. 2009. [Prevalence of non-tumorous canine dermatopathies in dogs from the municipality of Santa Maria, Rio Grande do Sul, Brazil (2005-2008).] Prevalência das dermatopatias não-tumorais em cães do município de Santa Maria, Rio Grande do Sul (2005-2008). Pesquisa Veterinária Brasileira 29(2):157-162. Departamento de Patologia, Universidade Federal de Santa Maria, 97105-900 Santa Maria, RS, Brazil. E-mail: teitsouza@yahoo.com.br

The current study was aimed at determine the prevalence of non-tumorous canine dermatopathies affecting dogs from the municipality of Santa Maria, Rio Grande do Sul, Brazil. From March 2005 to June de 2008, the authors followed-up canine dermatological cases from two sources: those referred to the Dermatology Sector of the Veterinary Teaching Hospital at the Universidade Federal de Santa Maria and those from a private practice. During this period 480 dogs with dermatological problems were examined; in 393 (81.9\%) it was possible to establish a definitive diagnosis and in $87(18.1 \%)$ the diagnosis was inconclusive. Four hundred and twenty four primary diagnosis and 78 secondary diagnosis were performed in the 393 dogs with conclusive diagnosis, totaling 502 diagnosis. The distribution of the diagnosis according to the categories of diagnosed dermatopathies was as follows: Allergic (190/502 [37.8\%]), bacterial (103/502 [20.5\%]), parasitic (97/502 [19.3\%]), environmental (28/502 [5,6\%]), mycotic (20/502 [4.0\%]), endocrine (13/502 [2.6\%]), keratinization disturbances (11/502 [2.2\%]), psychogenic (9/502 [1.8\%]), acquired alopecias $(6 / 502[1.2 \%])$, autoimmune (6/502 [1.2\%]), inherited (6/502 [1.2\%]), pigmentary disturbances (1/502 [0.2\%], nutritional (1/502 [0.2\%]), and sundry conditions (11/502 [2.2\%]). In general, the ten most frequently diagnosed non-tumorous dermatopathies in decreasing order of frequency were: Atopy, flea bite allergic dermatitis, bacterial folliculitis, demodectic mange, deep bacterial folliculitis/furunculosis, sarcoptic mange, myiasis, food allergy, traumatic pyoderma, and Malassezia dermatitis. These 10 conditions together made up approximately for three quarters of all canine skin diseases diagnosed in the current study.
\end{abstract}

INDEX TERMS: Diseases of dogs, skin diseases, dermatology, dermatopathology.

${ }^{1}$ Recebido em 18 de dezembro de 2008.

Aceito para publicação em 16 de janeiro de 2009.

Parte da tese de doutorado do primeiro autor.

2 Programa de Pós-Graduação em Medicina Veterinária, área de concentração em Patologia Veterinária, Centro de Ciências Rurais (CCR), Universidade Federal de Santa Maria (UFSM), Camobi, Santa Maria, RS 97105-900, Brasil. *Autor para correspondência: teitsouza @ yahoo.com.br

${ }^{3}$ Departamento de Patologia, Centro de Ciências da Saúde, UFSM, Santa Maria, RS.

${ }^{4}$ Departamento de Clínica de Pequenos Animais, CCR, UFSM, Santa Maria. RS.

${ }^{5}$ Médica Veterinária autônoma, Bem Estar Animal Consultório Veterinário, Rua Pedro de Oliveira 145, Km 3, Santa Maria, RS 97095-520.

${ }^{6}$ Bolsista de Iniciação Científica do CNPq junto ao Departamento de Patologia da UFSM, Santa Maria, RS.
RESUMO.- Este estudo teve como objetivo principal determinar a prevalência das dermatopatias não-tumorais que acometem cães do município de Santa Maria, Rio Grande do Sul, Brasil. Para isso, foram acompanhados os atendimentos dermatológicos no Hospital Veterinário Universitário, Universidade Federal de Santa Maria, e em um consultório veterinário particular no período de março de 2005 a junho de 2008. Durante esse período foram atendidos 480 cães com problemas dermatológicos, desses, em $393(81,9 \%)$ foi possível estabelecer o diagnóstico definitivo e em $87(18,1 \%)$ o diagnóstico não foi conclusivo. Esses 393 cães com diagnóstico conclusivo totalizaram 502 diagnósticos, sendo 424 diagnósticos pri- 
mários e 78 diagnósticos secundários. A distribuição dos diagnósticos em relação às categorias de dermatopatias diagnosticadas foi a seguinte: dermatopatias alérgicas (190/502 [37,8\%]), dermatopatias bacterianas (103/502 $[20,5 \%])$, dermatopatias parasitárias (97/502 [19,3\%]), dermatopatias relacionadas ao ambiente $(28 / 502$ [5,6\%], dermatopatias fúngicas (20/502 [4,0\%]), dermatopatias endócrinas (13/502 [2,6\%]), defeitos da ceratinização (11/ $502[2,2 \%])$, dermatopatias psicogênicas (9/502 [1,8\%]), alopecias adquiridas $(6 / 502[1,2 \%])$, dermatopatias autoimunes $(6 / 502[1,2 \%])$, dermatopatias hereditárias $(6 / 502$ $[1,2 \%])$, anormalidades pigmentares $(1 / 502$ [0,2\%], dermatopatias nutricionais $(1 / 502[0,2 \%])$ e outras dermatopatias $(11 / 502[2,2 \%])$. No geral, as 10 principais dermatopatias não-tumorais, em ordem decrescente de freqüência, foram: atopia, dermatite alérgica à picada de pulga, foliculite bacteriana superficial, sarna demodécica, foliculite bacteriana profunda/furunculose, sarna sarcóptica, míase, alergia alimentar, dermatite piotraumática e malassezíase. Essas 10 condições perfizeram juntas aproximadamente três quartos de todas as doenças de pele de cães diagnosticadas neste estudo.

TERMOS DE INDEXAÇÃO: Doenças de cães, doenças de pele, dermatologia, dermatopatologia.

\section{INTRODUÇÃO}

Na medicina veterinária, a dermatologia é uma área em ascensão. Acredita-se que hoje, entre $20 \%$ e $75 \%$ dos atendimentos veterinários realizados em clínicas e hospitais de pequenos animais estejam diretamente relacionados a problemas dermatológicos (Scott et al. 2001). Um estudo norte-americano (Ralston Purina Company 1989) indicou que $25 \%$ de todas as atividades relacionadas com pequenos animais envolviam o diagnóstico e o tratamento de problemas com a pele e a pelagem; outro estudo (Alpo Veterinary Panel 1985), com a participação de 2.540 clínicos de pequenos animais nos Estados Unidos, mostrou que as doenças de pele são os principais motivos de visita ao veterinário. Essa alta prevalência se deve, provavelmente, ao fato de que alterações de pele chamam a atenção e freqüentemente causam repulsa, fazendo com que o proprietário procure auxílio veterinário (Souza et al. 2006).

Com base nesse aspecto epidemiológico, o estudo das doenças de pele que afetam cães e gatos se torna cada vez mais importante, tanto para os clínicos de pequenos animais como para os patologistas que têm interesse em dermatopatologia. Entretanto, embora a literatura internacional sobre dermatologia seja vasta, há pouca informação disponível sobre a prevalência das dermatopatias de acordo com as diferentes regiões geográficas (Scott et al. 2001). Além disso, os poucos estudos epidemiológicos existentes são, na grande maioria, internacionais (Sischo et al. 1989, Scott \& Paradis 1990, Hill et al. 2006) e podem não refletir a situação regional brasileira. O objetivo deste estudo foi determinar a prevalência das dermatopatias não-tumorais que afetam cães no município de Santa Maria, Rio Grande do Sul, Brasil, a fim de permitir a orientação dos clínicos de pequenos animais de nossa região em suas suspeitas clínicas quando do atendimento de cães com problemas dermatológicos.

\section{MATERIAL E MÉTODOS}

Foram acompanhados os atendimentos dermatológicos de cães no Hospital Veterinário Universitário da Universidade Federal de Santa Maria (HVU-UFSM) e em um consultório veterinário particular do mesmo município no período de março de 2005 a junho de 2008. Dos atendimentos realizados, tanto no HVUUFSM como no consultório veterinário particular, foram incluídos apenas os casos acompanhados pelo primeiro autor.

Uma ficha dermatológica foi elaborada a fim de proporcionar uma sistemática ao processo de colheita de dados clínicos e de resultados de exames complementares. Os diagnósticos dermatológicos foram definidos pelos clínicos participantes do estudo, entretanto, para que um determinado caso pudesse fazer parte do estudo, o diagnóstico seguiu os critérios padrão estabelecidos pelos principais livros que tratam de doenças de pele de cães (Locke et al. 1993, Yager \& Scott 1993, Yager \& Wilcock 1994, Wilkinson \& Harvey 1996, Willemse 1998, Scott et al. 2001, Medleau \& Hnilika 2003, Harvey \& McKeever 2004, Gross et al. 2005, Ginn et al. 2007, Hargis \& Ginn 2007). Assim, em muitas situações, foi necessária a realização de exames complementares a fim de confirmar ou excluir determinadas possibilidades diagnósticas, dentre eles: bacteriológico, micológico, parasitológico, citopatológico, histopatológico, tricograma, dosagens hormonais, testes bioquímicos, hemograma e diagnóstico por imagem. Nos casos em que o diagnóstico foi estabelecido por meio de exame histopatológico, esse exame foi realizado no Laboratório de Patologia Veterinária da Universidade Federal de Santa Maria (LPV-UFSM). Alguns casos necessitaram confirmação terapêutica para estabelecer o diagnóstico. Nesse contexto, cães que não compareceram para re-avaliação foram excluídos do estudo.

Os diagnósticos foram agrupados nas seguintes categorias: dermatopatias alérgicas, dermatopatias bacterianas, dermatopatias parasitárias, dermatopatias fúngicas, dermatopatias relacionadas ao ambiente, dermatopatias endócrinas, defeitos da ceratinização, dermatopatias psicogênicas, dermatopatias auto-imunes, alopecias adquiridas, anormalidades pigmentares, dermatopatias hereditárias e dermatopatias nutricionais. As dermatopatias que não foram classificadas em nenhum desses tópicos foram agrupadas sob a expressão "outras dermatopatias". Os casos em que mesmo após a avaliação clínica e a realização dos exames complementares específicos não foi possível estabelecer um diagnóstico definitivo foram agrupados como inconclusivos.

\section{RESULTADOS}

De março de 2005 a junho de 2008, 480 cães foram examinados devido a algum tipo de distúrbio dermatológico não-tumoral. Dos 480 cães, 275 (57,3\%) eram fêmeas e $205(42,7 \%)$ eram machos, 350 (72,9\%) eram de raça pura e $130(27,1 \%)$ não tinham raça definida. As raças mais prevalentes incluíram: Dachshund (52/480 [10,8\%]), Poodle (38/480 [7,9\%]), Yorkshire Terrier (29/480 [6,0\%]), Pinscher (25/480 [5,2\%]), Cocker Spaniel (21/480 [4,4\%]), Labrador Retriever (20/480 [4,2\%]), Boxer (17/480 [3,5\%]), 
Pastor Alemão (16/480 [3,3\%]), Rottweiler (14/480 [2,9\%]), Pitt Bull (13/480 [2,7\%]) e Akita (12/480 [2,5\%]). O restante dos $93(19,4 \%)$ cães de raça pura pertencia a outras 26 raças diferentes.

Em $323(67,3 \%)$ casos foi realizado algum tipo de exame complementar que auxiliasse na confirmação ou exclusão dos diagnósticos. No total foram realizados 427 exames que se distribuíram da seguinte maneira: parasitológico (199/427 [46,6\%]), histopatológico (64/427 [15,0\%]), micológico (61/427 [14,3\%]), citopatológico (46/ $427[10,8 \%])$, testes bioquímicos $(23 / 427$ [5,4\%]), hemograma (12/427 [2,8\%]), dosagens hormonais (7/427 $[1,6 \%])$, tricograma $(7 / 427[1,6 \%])$, diagnóstico por imagem $(6 / 427$ [1,4\%]) e bacteriológico $(2 / 427$ [0,5\%]).

Dos 480 cães examinados, em 393 (81,9\%) foi possível estabelecer o diagnóstico definitivo e em $87(18,1 \%)$ o diagnóstico não foi conclusivo. Dos 393 cães com diagnóstico conclusivo, $362(92,1 \%)$ apresentavam apenas uma doença de pele primária e 31 (7,9\%) apresentavam duas doenças de pele primárias e distintas (independentes), totalizando 424 diagnósticos primários. Dos 393 cães com diagnóstico conclusivo, 56 (14,2\%) apresentavam uma ou mais doenças de pele secundárias, totalizando 78 diagnósticos secundários. A soma dos diagnósticos primários com os diagnósticos secundários totalizou 502 diagnósticos.

Em relação à distribuição das diferentes categorias de diagnósticos primários e secundários, a prevalência foi a seguinte: dermatopatias alérgicas (190/502 [37,8\%]), dermatopatias bacterianas $(103 / 502$ [20,5\%]), dermatopatias parasitárias $(97 / 502[19,3 \%])$, dermatopatias relacionadas ao ambiente (28/502 [5,6\%], dermatopatias fúngicas $(20 / 502[4,0 \%])$, dermatopatias endócrinas (13/502 $[2,6 \%])$, defeitos da ceratinização (11/502 [2,2\%]), dermatopatias psicogênicas $(9 / 502[1,8 \%])$, alopecias adquiridas $(6 / 502$ [1,2\%]), dermatopatias auto-imunes $(6 / 502$ $[1,2 \%])$, dermatopatias hereditárias $(6 / 502[1,2 \%])$, anormalidades pigmentares $(1 / 502$ [0,2\%], dermatopatias nutricionais $(1 / 502$ [0,2\%]) e outras dermatopatias (11/502 [2,2\%]). A distribuição dos diagnósticos primários e secundários de acordo com as diferentes categorias de doenças cutâneas de cães pode ser contemplada no Quadro 1.

\section{DISCUSSÃO}

Durante o período do estudo, no Hospital Veterinário Universitário da Universidade Federal de Santa Maria (HVUUFSM) e em um consultório particular do mesmo município, foram examinados 480 cães com algum tipo de distúrbio dermatológico não-tumoral. Desses, foi possível estabelecer um diagnóstico definitivo em $81,9 \%$. Esse resultado é semelhante ao descrito por outros autores (Hill et al. 2006) em um estudo que utilizou 559 cães e teve uma prevalência de $77,3 \%$ de diagnósticos conclusivos.

De acordo com os resultados aqui descritos, as dermatopatias alérgicas e bacterianas são as duas categori- as de doenças de pele mais prevalentes no município de Santa Maria, Rio Grande do Sul (37,8\% e 20,5\%, respectivamente). Esse resultado guarda tanto semelhanças quanto diferenças com outros estudos de prevalência de doenças dermatológicas realizados em vários locais do mundo. Na América do Norte, o mais famoso estudo sobre prevalência de doenças de pele em cães, realizado em 1983 e que teve como base os atendimentos $(n=11.456)$ realizados em 17 hospitais veterinários de 17 diferentes estados (16 nos Estados Unidos e um no Canadá) (Sischo et al. 1989), demonstrou que as dermatopatias alérgicas e bacterianas são as duas principais categorias de doenças de pele nessa espécie. Excluindo-se os tumores de pele que fizeram parte do referido estudo, essas duas categorias contribuíram com $52,2 \%$ e $22,7 \%$ do total de diagnósticos estabelecidos no período, respectivamente.

No Canadá, um estudo realizado em 1988, mas que contou com um número muito menor de cães $(n=419)$ e foi conduzido em apenas em um hospital veterinário (Scott \& Paradis 1990), demonstrou que as dermatopatias bacterianas são a categoria mais importante de doenças de pele. Nesse estudo, tais doenças foram um pouco mais prevalentes do que as dermatopatias alérgicas. Excluindo-se os tumores de pele que fizeram parte do referido estudo, essas duas categorias contribuíram com $27,2 \%$ e $25,0 \%$ do total de diagnósticos estabelecidos no período, respectivamente.

$\mathrm{Na}$ Inglaterra, semelhantemente ao que ocorre no Canadá, as dermatopatias bacterianas são mais freqüentes do que as dermatopatias alérgicas. Essa prevalência foi traçada em um estudo $(n=559)$ realizado por uma escola de veterinária entre os anos de 1998 e 2001 (Hill et al. 2006). Excluindo-se os tumores de pele que fizeram parte do referido estudo, essas duas categorias contribuíram com $20,7 \%$ e $15,8 \%$ do total de diagnósticos estabelecidos no período, respectivamente.

Quando comparamos os resultados por nós aqui descritos com os encontrados pelos autores desses outros três estudos, pôde-se perceber que a prevalência das dermatopatias bacterianas é relativamente semelhante, mas a prevalência das dermatopatias alérgicas é totalmente diferente. Essa marcada diferença se deve principalmente a prevalência da dermatite alérgica à picada de pulga (DAPP). No nosso estudo, DAPP perfez $16,5 \%$ do total de diagnósticos estabelecidos, o que contrasta grandemente com os resultados encontrados nesses outros três estudos, nos quais a DAPP perfez 42,3\% (Sischo et al. 1989), 7,0\% (Hill et al. 2006) e 3,7\% (Scott \& Paradis 1990) do total de diagnósticos estabelecidos. Em um dos estudos (Sischo et al. 1989), observou-se também um contraste na prevalência da DAPP de acordo com cada região avaliada. Em 15 dos 17 hospitais veterinários distribuídos em cinco das seis regiões avaliadas (nordeste, meio-oeste, oeste, sudeste e sudoeste), a prevalência da DAPP oscilou ao redor de $30 \%-40 \%$, entretanto, em dois hospitais veterinários, localizados na mesma região (pla- 
Quadro 1. Distribuição dos diagnósticos primários e secundários de acordo com as diferentes categorias de doenças cutâneas de cães

\begin{tabular}{|c|c|c|c|c|c|}
\hline Diagnósticos & Total & $\%$ & Diagnósticos & Total & $\%$ \\
\hline Dermatopatias alérgicas & 190 & 37,8 & Defeitos da ceratinização & 11 & 2,2 \\
\hline Atopia & 84 & 16,7 & Dermatite seborréica & 8 & 1,6 \\
\hline DAPPa & 83 & 16,5 & $\mathrm{SCMO}^{\mathrm{b}}$ & 3 & 0,6 \\
\hline Alergia alimentar & 16 & 3,2 & Dermatopatias psicogênicas & 9 & 1,8 \\
\hline Dermatite de contato alérgico & 3 & 0,6 & Dermatite acral por lambedura & 9 & 1,8 \\
\hline Furunculose eosinofílica da face & e 2 & 0,4 & Alopecias adquiridas & 6 & 1,2 \\
\hline Urticária & 2 & 0,4 & Alopecia pós-tosa & 2 & 0,4 \\
\hline Dermatopatias bacterianas & 103 & 20,5 & Defluxo anagênico & 2 & 0,4 \\
\hline Foliculite superficial & 64 & 12,7 & Alopecia por tração & 1 & 0,2 \\
\hline Foliculite profunda/furunculose & 23 & 4,6 & Displasia folicular & 1 & 0,2 \\
\hline Furunculose interdigital & 10 & 2,0 & Dermatopatias auto-imunes & 6 & 1,2 \\
\hline Impetigo & 4 & 0,8 & Complexo pênfigo ${ }^{c}$ & 4 & 0,8 \\
\hline Pioderma do Pastor Alemão & 2 & 0,4 & Lúpus eritematoso discóide & 2 & 0,4 \\
\hline Dermatopatias parasitárias & 97 & 19,3 & Dermatopatias hereditárias & 6 & 1,2 \\
\hline Sarna demodécica & 53 & 10,5 & Calvície padrão & 2 & 0,4 \\
\hline Sarna sarcóptica & 19 & 3,8 & Displasia folicular do pêlo preto & 2 & 0,4 \\
\hline Miíase ${ }^{\mathrm{d}}$ & 18 & 3,6 & Seborréia primária & 2 & 0,4 \\
\hline Puliciose & 3 & 0,6 & Anormalidades pigmentares & 1 & 0,2 \\
\hline Pediculose & 2 & 0,4 & Acantose nigricante do Dachshund & d 1 & 0,2 \\
\hline Tungíase & 2 & 0,4 & Dermatopatias nutricionais & 1 & 0,2 \\
\hline Dermatopatias ambientais & 28 & 5,6 & Dermatose responsiva ao zinco & 1 & 0,2 \\
\hline Dermatite piotraumática & 15 & 3,0 & Outras dermatopatias & 11 & 2,2 \\
\hline Pioderma do calo & 8 & 1,6 & DLGEJe & 5 & 1,0 \\
\hline Dermatite de contato irritante & 3 & 0,6 & Adenite sebácea & 2 & 0,4 \\
\hline Intertrigo & 1 & 0,2 & Ceratose liquenóide & 1 & 0,2 \\
\hline Reação a corpo estranhof & 1 & 0,2 & Ceratose seborréica & 1 & 0,2 \\
\hline Dermatopatias fúngicas & 20 & 4,0 & Doença do coxim fendido & 1 & 0,2 \\
\hline Dermatite por Malasseziag & 14 & 2,8 & SGPEh & 1 & 0,2 \\
\hline Dermatofitose ${ }^{i}$ & 6 & 1,2 & & & \\
\hline Dermatopatias endócrinas & 13 & 2,6 & & & \\
\hline Hipotireoidismo & 5 & 1,0 & & & \\
\hline Hiperadrenocorticismo & 4 & 0,8 & & & \\
\hline Hiperestrogenismoj & 2 & 0,4 & & & \\
\hline Alopecia $X^{k}$ & 1 & 0,2 & & & \\
\hline Nanismo hipofisário & 1 & 0,2 & Total & 502 & - \\
\hline
\end{tabular}

a Dermatite alérgica à picada de pulga; ${ }^{b}$ seborréia canina da margem da orelha ou dermatite seborréica da margem da orelha; ${ }^{c}$ dos quatro casos de pênfigo, três eram foliáceo e um era eritematoso; ${ }^{d}$ esses 18 casos de miíase obrigatória incluem 12 casos de miíase cutâneo-traumática causada por Cochliomyia hominivorax (vulgarmente bicheira) e seis casos de miíase furunculosa causada por Dermatobia hominis (vulgarmente berne); ${ }^{\text {e }}$ dermatite e linfadenite granulomatosa estéril juvenil; ${ }^{\dagger}$ espinho de ouriço-cacheiro (Coendou villosus); $\mathrm{g}$ inclui apenas casos de dermatite por Malassezia pachydermatis; ${ }^{\mathrm{h}}$ síndrome do granuloma e piogranuloma estéril; ${ }^{i}$ inclui apenas casos de dermatite por Microsporum canis; ${ }^{j}$ por alguns autores denominado como doença de pele associada ao tumor de células de Sertoli; ${ }^{k}$ por alguns autores denominada dermatose responsiva à castração/hormônio do crescimento.

nície) e que incluía o estado do Colorado, nos Estados Unidos, e a província de Saskatchewan, no Canadá, a prevalência da DAPP foi de apenas 3,5\%, semelhantemente à descrita no estudo canadense. Os autores do estudo (Sischo et al. 1989) atribuíram tamanha variação epidemiológica às diferenças climáticas, que fazem da pulga um ectoparasita variavelmente prevalente de acordo com o grau de umidade e temperatura. Com base nesse aspecto, que leva em conta apenas as diferenças climáticas nos locais em que foram conduzidos os quatro estudos que estamos comparando, talvez a muito menor prevalência da DAPP em nossa região, quando comparada à prevalência na maior parte dos Estados Unidos, tenha também uma relação direta com o clima.

No Rio Grande do Sul, os únicos dados epidemiológicos disponíveis sobre a prevalência de dermatopatias em cães são oriundos de dois estudos (um prospectivo e outro retrospectivo, respectivamente) que tiveram como base os atendimentos ( $n=250$ e $n=334$, respectivamente) realizados em um hospital veterinário de Porto Alegre, Rio Grande do Sul, em 2000-2001 e em 2007 (Machado et al. 2004, Bianchi et al. 2008). Esses estudos demonstraram que, na população avaliada, as dermatopatias alérgicas contribuem com $44 \%$ e $53 \%$ do total de diagnósticos estabelecidos e essas altas prevalências se devem, principalmente, a grande quantidade de diagnósticos de DAPP (28,4\% e $28,0 \%$ dos diagnósticos estabelecidos). Essas prevalências contrastam muito com a observada neste estudo (16,5\% dos diagnósticos estabelecidos) e nesse caso não há diferenças climáticas significativas entre as regiões comparadas que possam explicar tal variação epidemiológica. 
Outra diferença marcante entre este e os outros três estudos anteriormente citados (Sischo et al. 1989, Scott \& Paradis 1990, Hill et al. 2006) está na prevalência das dermatopatias parasitárias. Conforme os resultados aqui descritos, dermatopatias parasitárias são a terceira categoria mais prevalente de dermatopatias não-tumorais em nossa região, contribuindo com $19,3 \%$ do total de diagnósticos estabelecidos. Excluindo-se os tumores de pele que fizeram parte dos três referidos estudos, essa categoria contribuiu com $7,7 \%, 6,6 \%$ e $4,6 \%$ do total de diagnósticos estabelecidos no período, respectivamente. Essa menor prevalência das dermatopatias parasitárias se deve principalmente ao menor número de casos de sarna demodécica $(5,6 \%, 2,5 \%$ e $1,3 \%$ do total de diagnósticos estabelecidos, respectivamente), uma doença que se mostrou altamente prevalente em nossa região, contribuindo com $10,5 \%$ total de diagnósticos estabelecidos neste estudo. Embora não saibamos o exato motivo pelo qual a sarna demodécica é tão comum em nosso meio, é possível que isso se deva, pelo menos em parte, a diferenças na conduta frente ao cão com a doença. Tanto nos Estados Unidos como no Canadá e na Inglaterra, os veterinários não tratam cães com sarna demodécica que se destinem a reprodução. Assim, a esterilização é prática corrente nesses países, o que faz com que os cães susceptíveis não possam reproduzir-se, diminuindo a prevalência da doença (Willemse 1998, Scott et al. 2001). Essa conduta é adotada desde 1981, quando a American Academy of Veterinary Dermatology (AAVD) emitiu uma resolução que determinava: "... todos os cães com sarna demodécica generalizada devem ser esterilizados para que a incidência da doença diminua." (Gross et al. 2005). No Brasil, embora a reprodução de cães que tiveram sarna demodécica seja desencorajada pelos veterinários, sabe-se que são poucos os proprietários e criadores que submetem seus cães a esterilização por esse motivo, o que acaba perpetuando linhagens familiares predispostas à doença.

Um importante resultado encontrado neste estudo foi a baixa prevalência das dermatopatias fúngicas, principalmente da dermatofitose $(1,2 \%$ do total de diagnósticos estabelecidos neste estudo). Essa baixa prevalência da dermatofitose também foi observada nos estudos canadense $(0,9 \%$ do total de diagnósticos estabelecidos) (Scott \& Paradis 1990$)$ e inglês $(0,2 \%$ do total de diagnósticos estabelecidos) (Hill et al. 2006). Tal resultado é contrário ao pensamento de alguns autores, os quais afirmam que dermatofitose tem prevalência entre $12,5 \%$ e $24,6 \%$ (AlDoory et al. 1968, Bone \& Jackson 1971), e de muitos clínicos de pequenos animais de nossa região e de outros locais do país, pois dermatofitose é ainda hoje um dos diagnósticos dermatológicos mais realizados na rotina da clínica de pequenos animais. Acreditamos que esse excesso de diagnósticos de dermatofitose se deva principalmente a ausência de confirmação laboratorial, visto a clássica manifestação macroscópica dessa dermatopatia (tinha ou ringworm) ser considerada por muitos clínicos como "altamente sugestivas" da doença. Assim, conforme alguns autores (Scott et al. 2001, Gross et al. 2005), quando se confia apenas nos sinais clínicos, a dermatofitose é grandemente superdiagnosticada.

Neste estudo foram incluídos como dermatofitose apenas casos confirmados laboratorialmente através de exames micológicos ou histopatológico. Assim, muitos casos suspeitos de dermatofitose por apresentarem tais lesões consideradas "altamente sugestivas" foram negativos no exame direto do pêlo e na cultura. Dos 480 cães incluídos neste estudo, 61 apresentavam tais lesões (12,7\%) e foram submetidos a testes micológicos que incluíram exame direto do pêlo e cultura. Apenas seis desses 61 cães $(9,8 \%)$ tiveram resultado positivo. Os outros 55 casos negativos $(90,2 \%)$ correspondiam a foliculite bacteriana, o que faz com que o aforisma "Se parece dermatofitose, provavelmente não é! Provavelmente é foliculite estafilocócica!", usado por muitos dermatologistas (Scott et al. 2001), deva ser realmente considerado no momento do diagnóstico. Essa baixa prevalência da positividade do exame micológico tem sido descrita por outros autores (Medleau \& Ristic 1992), o que confirma ainda mais essa hipótese. Em um estudo recente (Mottin et al. 2008), que avaliou através de cultura fúngica 154 amostras de pêlo de cães e gatos com lesões de pele associadas a diferentes doenças, apenas oito $(5,2 \%)$ foram positivos para dermatófitos. Em outro estudo (Machado et al. 2004), de 250 amostras de pêlos de cães com distúrbios dermatológicos diversos, apenas 19 (7,6\%) foram positivos para dermatófitos.

Outra diferença observada entre os resultados por nós encontrados e aqueles oriundos do estudo canadense está na prevalência das dermatopatias endócrinas. Conforme os resultados aqui descritos, dermatopatias endócrinas contribuíram com apenas $2,6 \%$ do total de diagnósticos estabelecidos. No estudo canadense (Scott \& Paradis 1990), dermatopatias endócrinas perfizeram $9,2 \%$ do total de diagnósticos estabelecidos. Inicialmente acreditamos que essa maior prevalência das dermatopatias endócrinas se devesse a uma maior expectativa de vida dos cães canadenses, visto que cães mais velhos são mais susceptíveis ao desenvolvimento de algumas endocrinopatias, como hiperadrenocorticismo e hipotireoidismo (Halliwell 1990), as duas doenças endócrinas mais prevalentes daquele estudo $(3,7 \%$ e $2,9 \%$ do total de diagnósticos estabelecidos, respectivamente). Entretanto, no outro estudo norte-americano e no estudo inglês, a prevalência das dermatopatias endócrinas foi ainda menor do que aquela observada por nós $(1,7 \%$ e $0,5 \%$ do total de diagnósticos estabelecidos, respectivamente). Assim, com base no fato de que a expectativa de vida dos cães americanos (Bronson 1982) e ingleses (Michell 1999) é semelhante (117 e 132 meses de idade, respectivamente) e ambas são muito diferentes da expectativa de vida dos cães no Brasil (36 meses de idade) (Bentubo et al. 2007), essa não pode ser a explicação para tal diferença epidemiológica. 


\section{CONCLUSÕES}

Os resultados deste estudo permitem concluir que as categorias de dermatopatias não-tumorais de cães do município de Santa Maria, Rio Grande do Sul, estão distribuídas da seguinte maneira: dermatopatias alérgicas, dermatopatias bacterianas, dermatopatias parasitárias, dermatopatias relacionadas ao ambiente, dermatopatias fúngicas, dermatopatias endócrinas, defeitos da ceratinização, dermatopatias psicogênicas, alopecias adquiridas, dermatopatias auto-imunes, dermatopatias hereditárias, anormalidades pigmentares, dermatopatias nutricionais e outras dermatopatias. No geral, as 10 principais dermatopatias não-tumorais (atopia, dermatite alérgica à picada de pulga, foliculite bacteriana superficial, sarna demodécica, foliculite bacteriana profunda/furunculose, sarna sarcóptica, miíase, alergia alimentar, dermatite piotraumática e malassezíase) perfazem juntas aproximadamente três quartos de todas as doenças de pele de cães diagnosticadas neste estudo. Esse achado reforça a idéia corrente de que poucas doenças de pele são responsáveis pela maior parte dos atendimentos dermatológicos.

\section{REFERÊNCIAS}

Alpo Veterinary Panel 1985. Dermatological problems head problem list. DVM Magazine s/v:22-23.

Al-Doory Y., Vice T.E. \& Olin D.V.M. 1968. A survey of ringworm in dogs and cats. J. Am. Vet. Med. Assoc. 153:429-432.

Bentubo H.D.L., Tomaz M.A., Bondan E.F. \& Lallo M.A. 2007. Expectativa de vida e causas de morte em cães na área metropolitana de São Paulo (Brasil). Ciência Rural 37:1021-1026.

Bianchi S.P., Correa R.K.R., Villa-Lobos W.O.R., Ferreira R.R. \& Machado M.L.S. 2008. Atendimentos realizados no ano de 2007 no Serviço de Dermatologia do Hospital de Clínicas Veterinárias da UFRGS. Anais $35^{\circ}$ Conbravet, Gramado, RS, s/p.

Bone W.J. \& Jackson W.F. 1971. Pathogenic fungi in dermatitis: Incidence in two small animal practices in Florida. Vet. Med. Small Anim. Clin. 66:140-142.

Bronson R.T. 1982. Variation in age at death of dogs of different sexes and breeds. Am. J. Vet. Res. 43:2057-2059.

Ginn P.E., Mansel J.E.K.L. \& Rakich P. M. 2007. Skin and appendages, p.553-781. In: Maxie M.G. (Ed.), Jubb, Kennedy, and Palmer's Pathology of Domestic Animals. Vol.2. 5th ed. Saunders Elsevier, Philadelphia. 771p.

Gross T.L., Ihrke P.J., Walder E.J. \& Affolter V.K. 2005. Skin diseases of the dog and cat. Clinical and histopathologic diagnosis. 2nd ed. Blackwell, Oxford. 932p.

Halliwell R.E.W. 1990. Skin diseases of old dogs and cats. Vet. Rec. 126:389-394.
Hargis A.M. \& Ginn P.E. 2007. The integument, p.1107-1261. In: McGavin M.D. \& Zachary J.F. (Ed.), Pathologic Basis of Veterinary Disease. 4th ed. Mosby Elsevier, St Louis. 1476p.

Harvey R.G. \& McKeever P.J. 2004. Manual Colorido de Dermatologia do Cão e do Gato: diagnóstico e tratamento. Revinter, Rio de Janeiro. 240 p.

Hill P.B., Lo A., Eden C.A.N., Huntley S., Morey V., Ramsey S., Richardson C., Smith D.J., Sutton C., Taylor M.D., Thorpe E., Tidmarsh R. \& Williams V. 2006. Survey of the prevalence, diagnosis and treatment of dermatological conditions in small animals in general practice. Vet. Rec. 158:533-539.

Locke P.H., Harvey R.G. \& Mason I.S. 1993. BSAVA Manual of Small Animal Dermatology. British Small Animal Veterinary Association, Cheltenham. 353p.

Machado M.L.S., Appelt C.E. \& Ferreiro L. 2004. Dermatófitos e leveduras isolados da pele de cães com dermatopatias diversas. Acta Scientiae Vet. 32:225-232.

Medleau L. \& Hnilica K.A. 2003. Dermatologia de Pequenos Animais: atlas colorido e guia terapêutico. Roca, São Paulo. 353p.

Medleau L. \& Ristic Z. 1992. Diagnosing dermatophytosis in dogs and cats. Vet. Med. 87:1086.

Michell A.R. 1999. Longevity of British breeds of dog and its relationships with sex, size, cardiovascular variables and disease. Vet. Rec. 145:625629.

Mottin V.D., Simões C., Albileira F., Chiminazzo C., Cereser V.H., Queirolo M.T., Oliveira S.J. \& Fischer C. 2008. Dermatopatias em pequenos animais na rotina clínica do HV-Ulbra, Canoas, RS: um estudo retrospectivo. Anais $35^{\circ}$ Conbravet, Gramado, RS, s/p.

Ralston Purina Company 1989. An Introduction to the Nutrition of Dogs and Cats. Veterinary Learning Systems, Trenton, Yardley, PA.

Scott D.W. \& Paradis M. 1990. A survey of canine and feline skin disorders seen in a university practice: Small Animal Clinic, University of Montréal, Saint-Hyacinthe, Québec (1987-1988). Can. Vet. J. 31:830-835.

Scott D.W., Miller D.H. \& Griffin C.E. 2001. Muller and Kirk's Small Animal Dermatology. 6th ed. Saunders, Philadelphia. 1528p.

Sischo W.M., Ihrke P.J. \& Franti C.E. 1989. Regional distribution of ten skin diseases in dogs. J. Am. Vet. Med. Assoc. 195:752-756.

Souza T.M., Fighera R.A., Irigoyen L.F. \& Barrros C.S.L. 2006. Estudo retrospectivo de 761 tumores cutâneos em cães. Ciência Rural 36:555560 .

Wilkinson G.T. \& Harvey R.G. 1996. Atlas Colorido de Dermatologia dos Pequenos Animais: guia para o diagnóstico. $2^{\mathrm{a}}$ ed. Manole, São Paulo. 304p.

Willemse T. 1995. Dermatologia Clínica de Cães e Gatos. 2ª ed. Manole, São Paulo. 141p.

Yager J.A. \& Scott D.W. 1993. The skin and appendages, p.531-738. In: Jubb K.V.F., Kennedy P.C. \& Palmer N. (Ed.), Pathology of Domestic Animals. Vol.1. 4th ed. Academic Press, San Diego. 780p.

Yager J.A. \& Wilcock B.P. 1994. Color Atlas and Text of Surgical Pathology of the Dog and Cat: Dermatopathology and skin tumors. Wolfe, London. 320p. 